\title{
مجالات مفتوحة للبحث في الاقنصاد الإسلامي
}

\section{هيئة التحرير}

يرى بعض الباحثين أنَّ الفكر الإسلامي المعاصر في بحال الاقتصاد انشغل -ـإلى حد

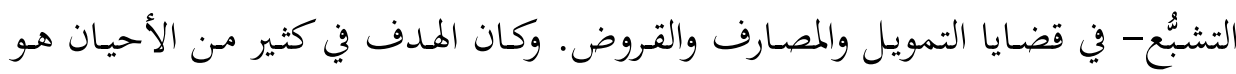

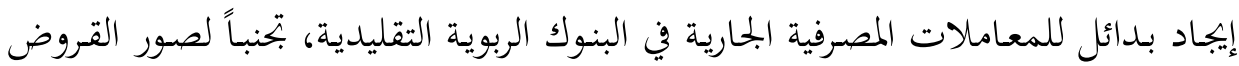

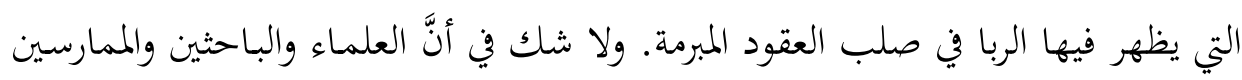

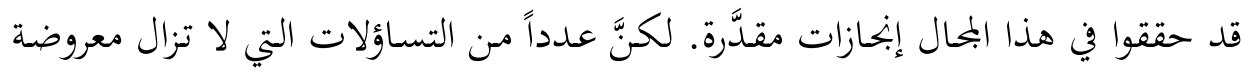

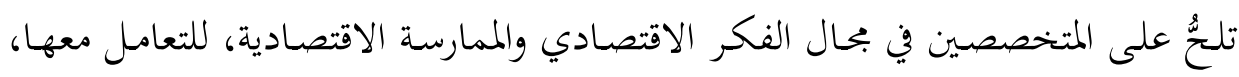
من أجل أن تصبح الإبحازات المشار إليها عناصر أساسية في بناء الاقتصاد الإسـلامي؛ فلسفةً ونظامـاً، وللنظر في الصـياغات العلميـة والعمليـة التي تسـهم في التأسيس لنظـام

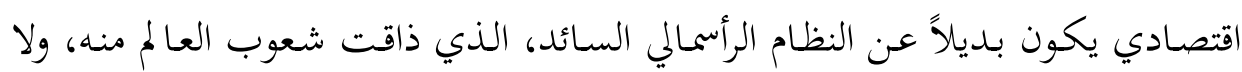

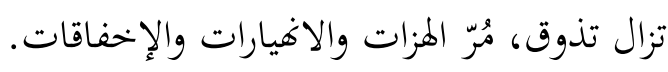

إنَّ فلسفة النظام الاقتصـادي الإسـلامي جـزءٌ مـن فلسفة الإسـلام في بنـاء البحتمـع

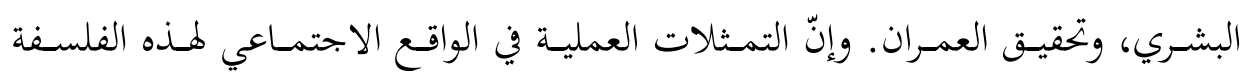

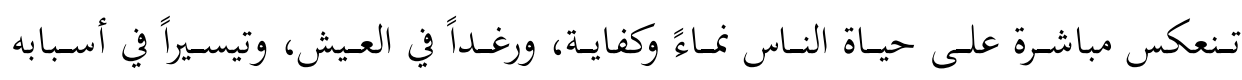

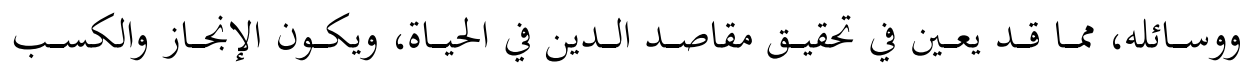

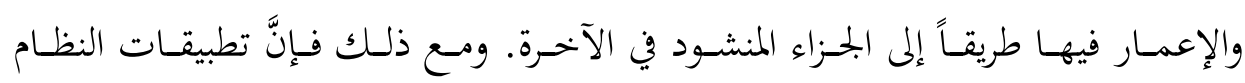

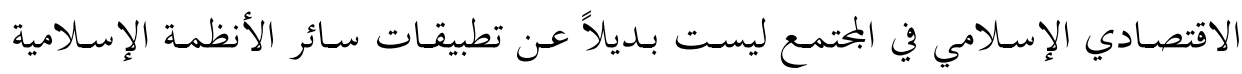

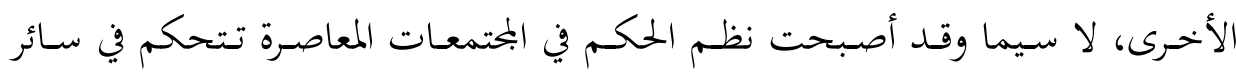

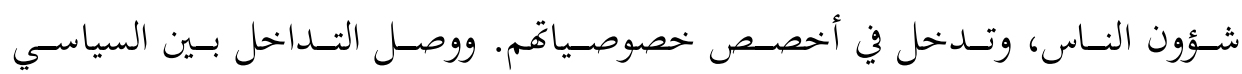

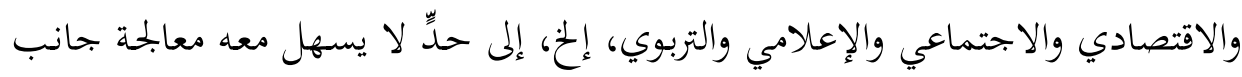

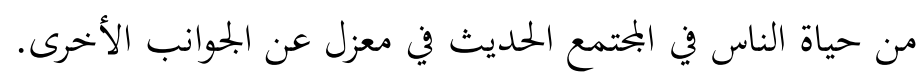


ولعل هذه الحقيقة تنبه إلى ضرورة الوعي على متطلبات الإصلاح في واقع البحتمعات

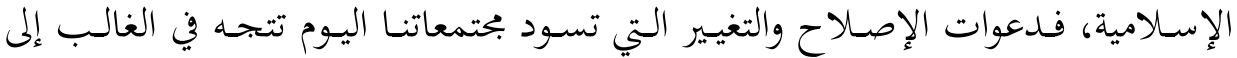

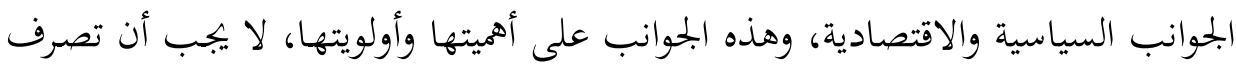
النظر عن ضرورة توسيع دائرة الدعوة إلى الإصلاح إلى سائر الجوانب الأخرى، لا سيما

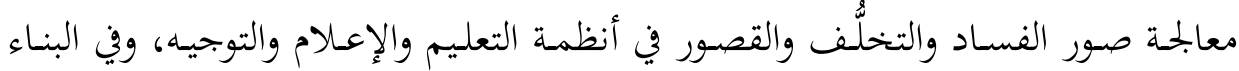

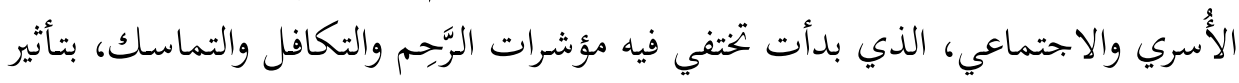

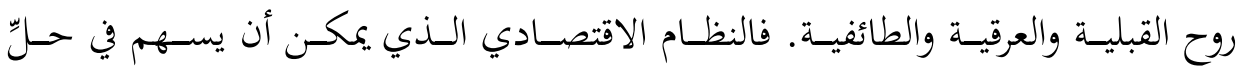

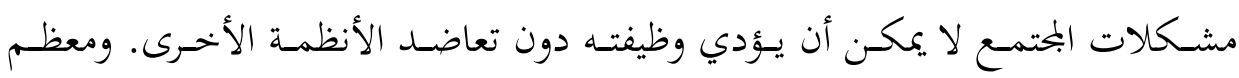

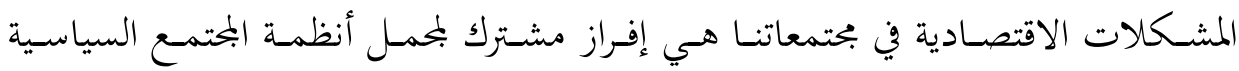

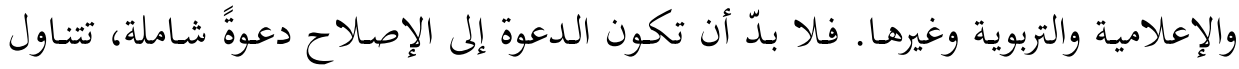

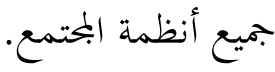

وعلى كل حـال فبإنَّ الحاجـةَ ماسّةٌٌ إلى تواصل البحـث والاجتهاد في تـدبير الثـأن

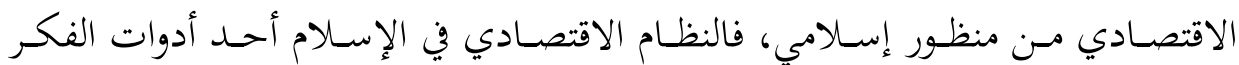

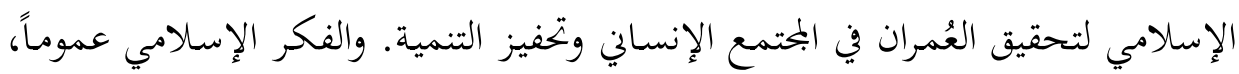

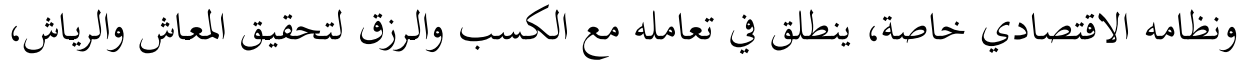

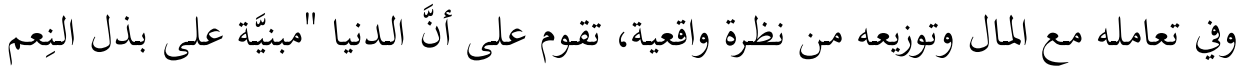

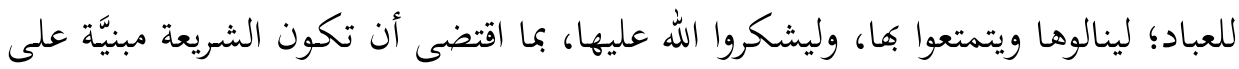

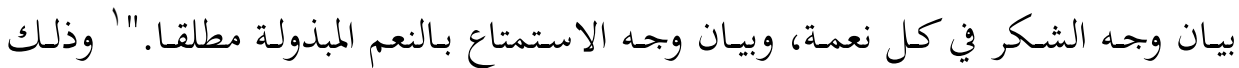

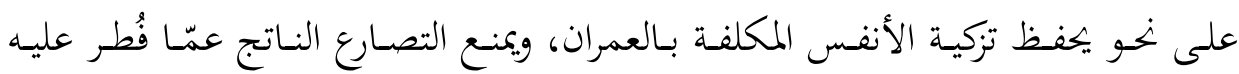

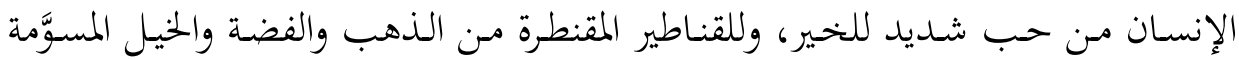

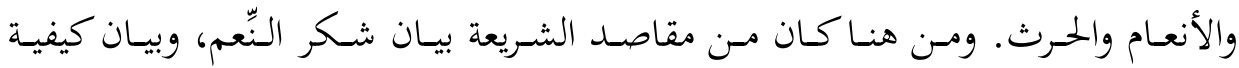

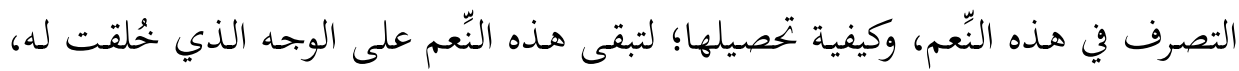

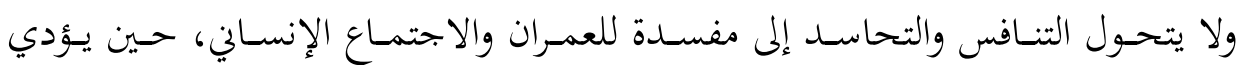

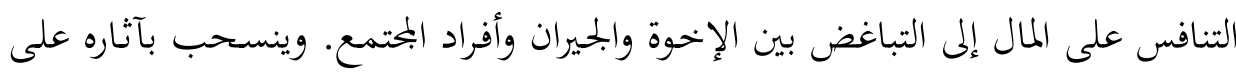
المستوى الدولي. ' الشاطبي، إبراهيم بن موسى. الموافقات، تحقيق: عبد الله دراز، بيروت: دار المعرفة، جr، ص ابr. 
V والات مفتوحة للبحث في الاقتصاد الإسلامي

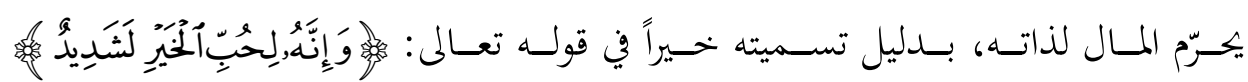

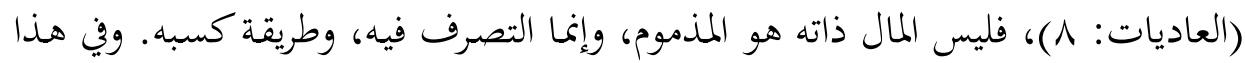

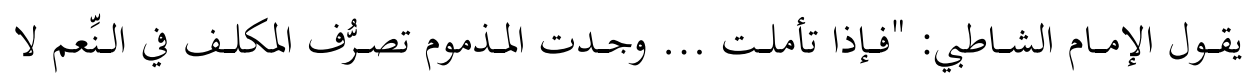

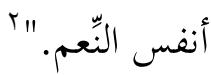

كما يرفض الإسلام تعطيل النّعم وتبرير هذا التعطيل دينياً كما فعل الجحاهليون حين

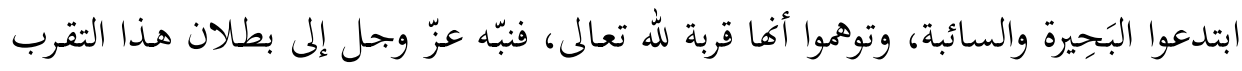

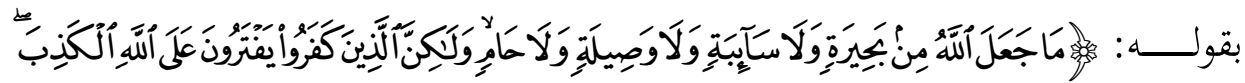

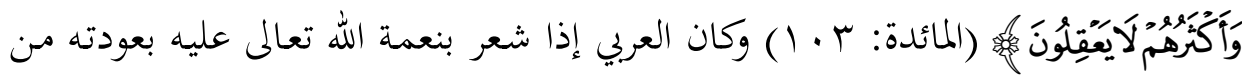

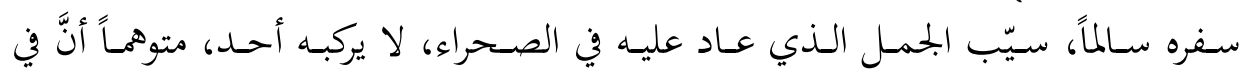

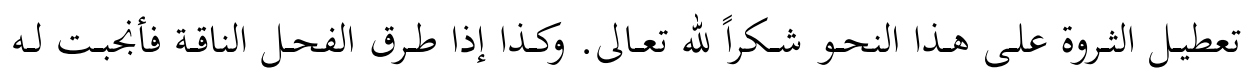

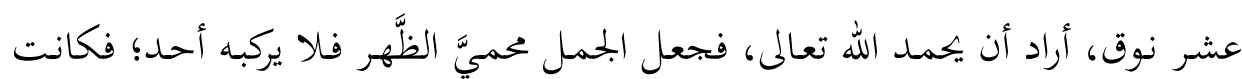

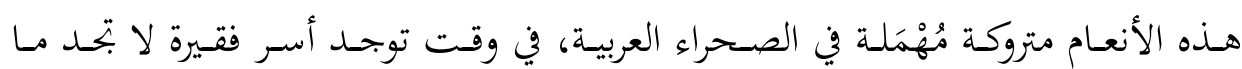

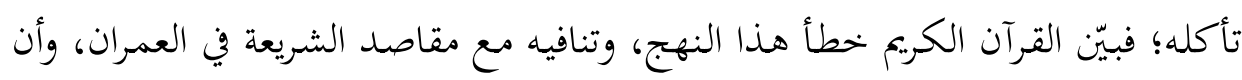

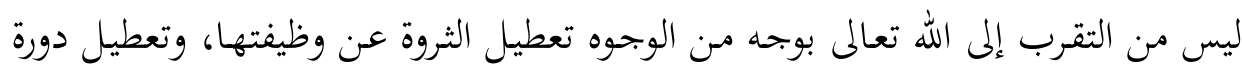
الإنتاج.

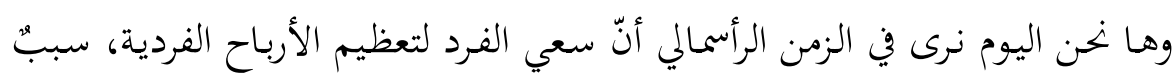

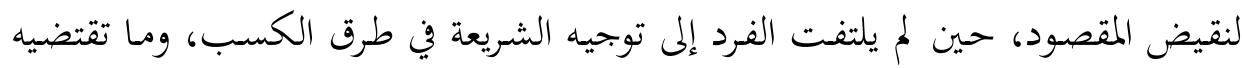

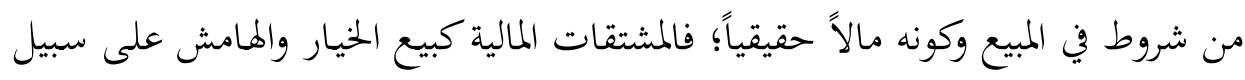

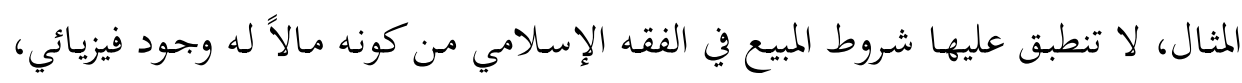

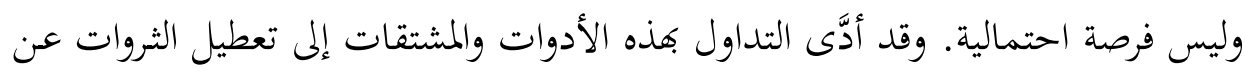

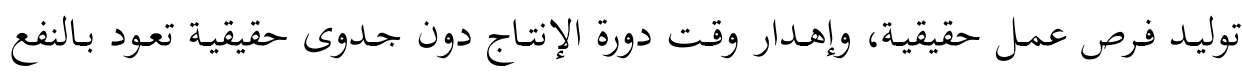

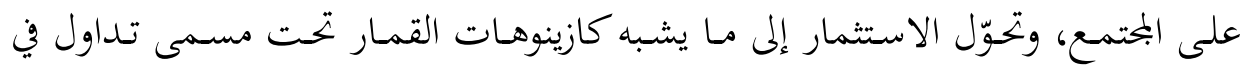




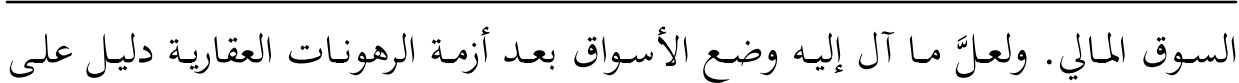

$$
\text { الخلل البيّن في هذه الأدوات الرأسمالية للاستثمار . }
$$

وفي المقابــل، حمـى الله المؤسســات الماليـة، الـتي التزمــت بالهـــي الإســالامي في

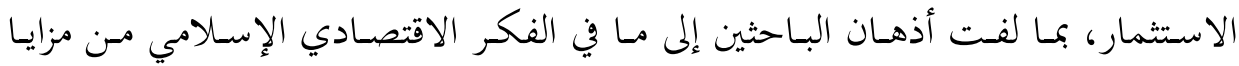

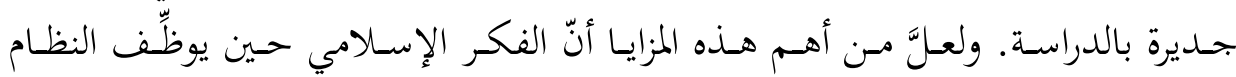

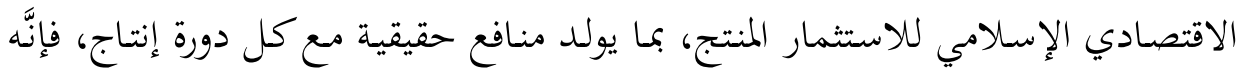

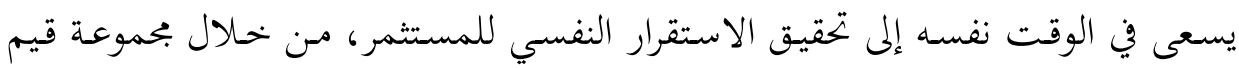

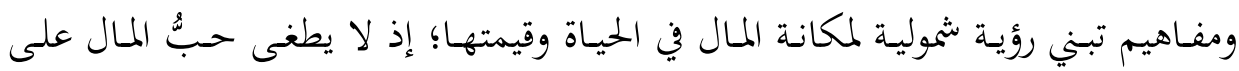

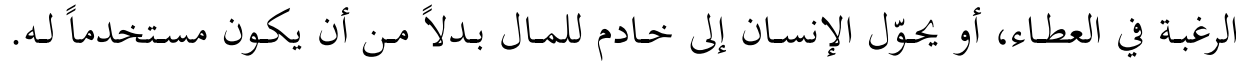

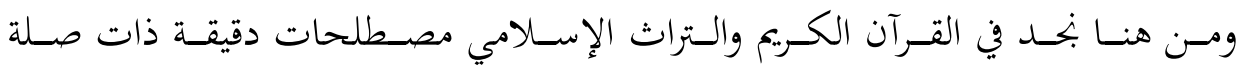

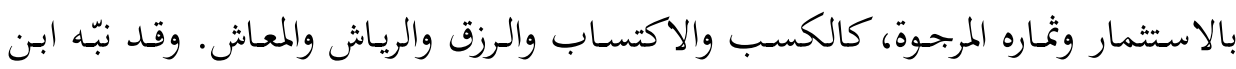
خلدون في المقدمة إلى هذه المصطلحات في باب الفرق بين الرزق والكسب. وفئ وفيه يقول: "اعلم أنَّ الإنسـان مفتقر بـالطبع إلى مـا يقوته و يموّنـهـ في حالاته وأطواره مـن لـدن

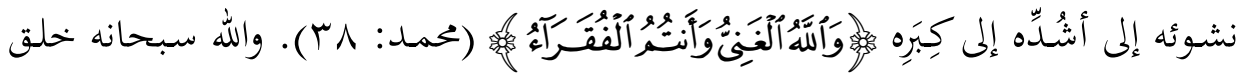

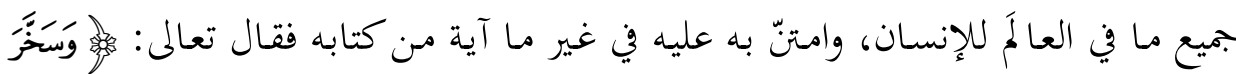

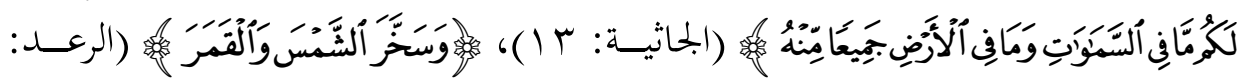

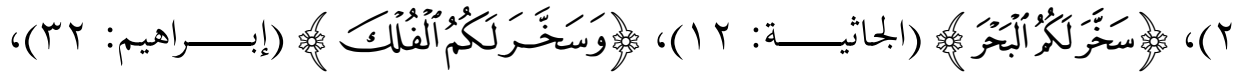

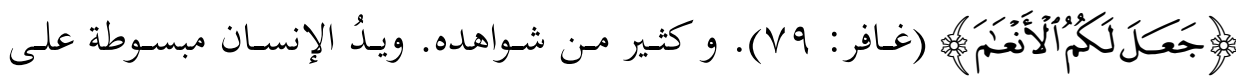

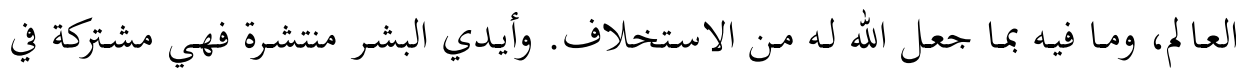

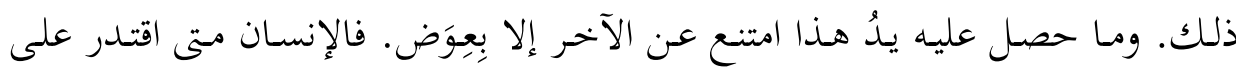

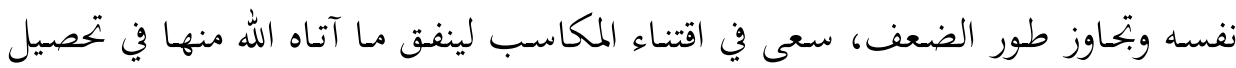

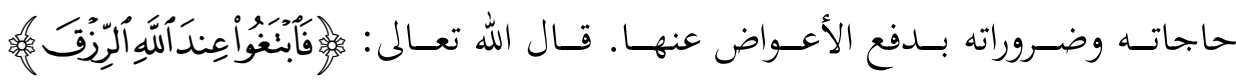

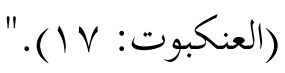

"وقد يكصل له ذلك بغير سعي كالمطر المصلح للزراعة وأمثاله. إلا أهـا إنَّا تكون

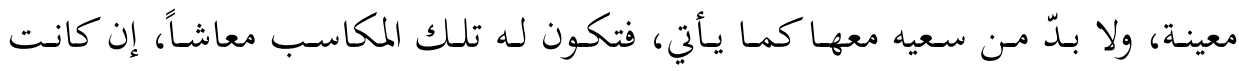




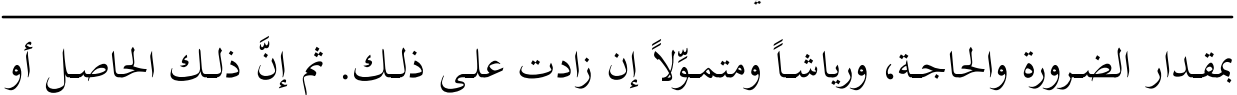
المقتنى إن عادت منفعته على العبد وحصلت له ثمرته من إنفاقه في مصالحه وحاجاته سُّميَّ

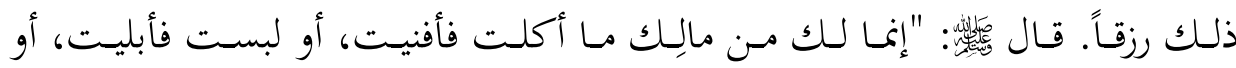

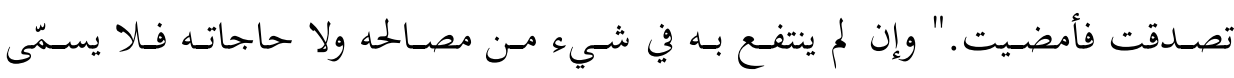

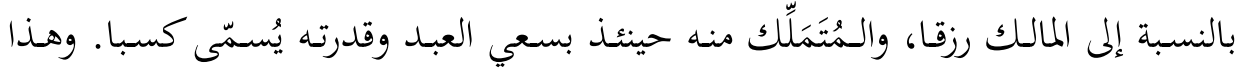

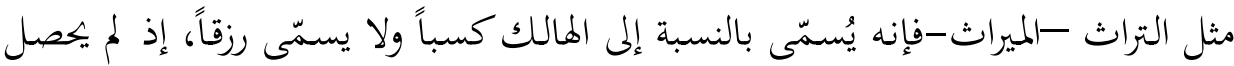

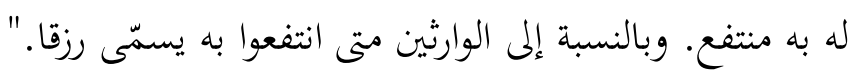
"هذا حقيقة مسمَّى الرزق عند أهل السنة..."

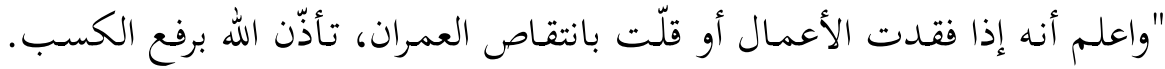

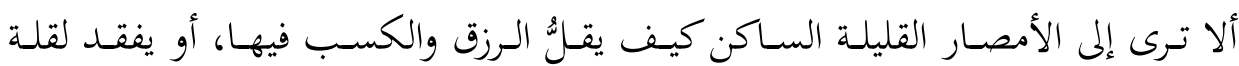

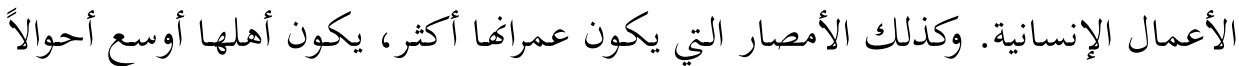

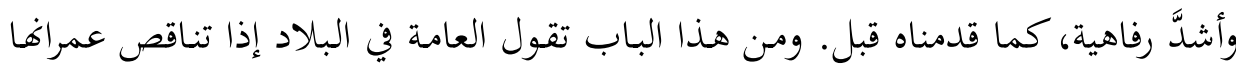

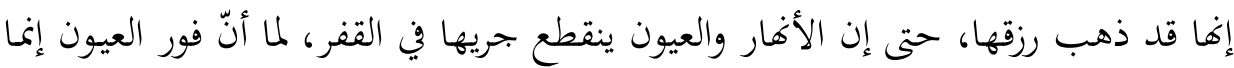

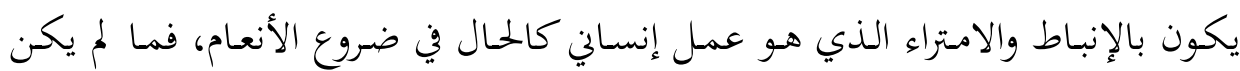

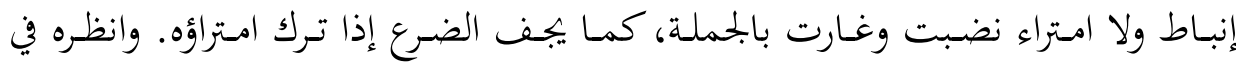

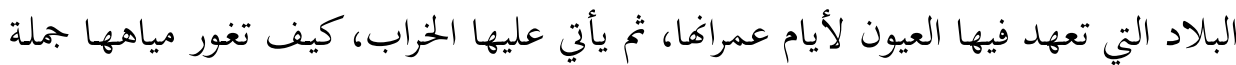

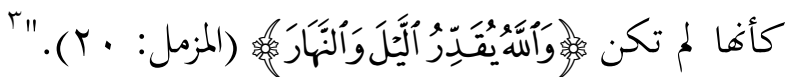
وترى في النص التراثي السابق عدداً من المفاهيم التي تعكس رؤية خختلفة عن الرؤية

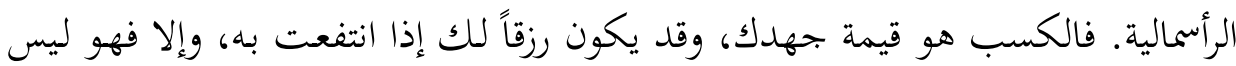

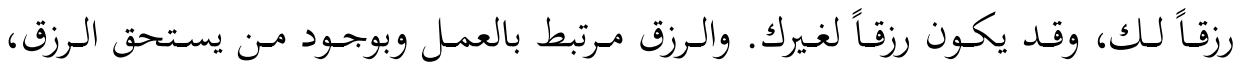
فالأهار مصدر للرزق ولذلك بنيت حولها المدن وكثر فيها الناس، وفي الصحراء يقلّ الماء وتقلّ فرص الرزق، ويقلّ العمل.

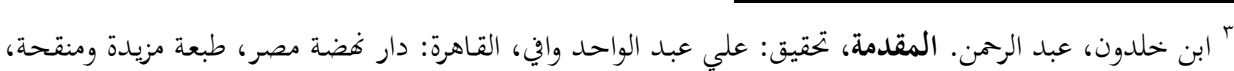

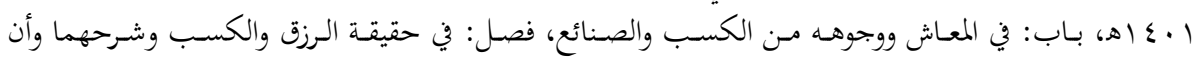

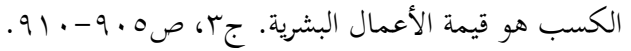


إذا أرادت الأمة أن تنهض بالاقتصاد الإسلامي، وتقيم بنيانه، لا بدّ لما من دراسات

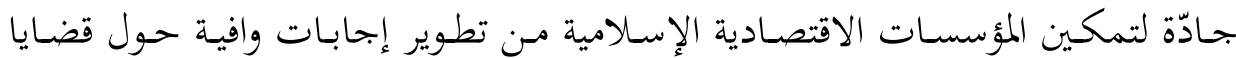
الاقتصاد الكلي والاقتصاد الجزئي على حد سواء، وشق الطرق اللازمة لتنمية حقيقة تقوم

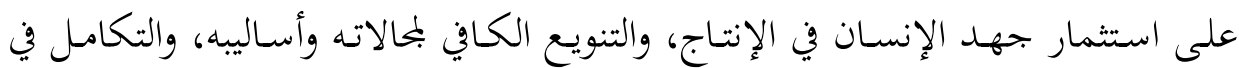
هـذه المحالات بـين بحتمعـات الأمهة، والتوزيـع العـادل لثروات الأمـة وبحتمعاتها، ومعالجحة

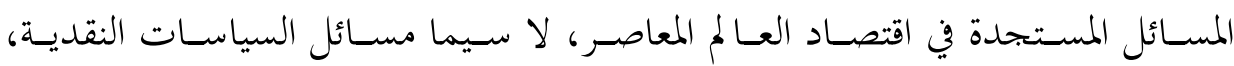
والاستثمار، والتمويل، وغيرها.

وقد جاء هذا العدد من بحلة إسلامية المعرفة مشتمالً على عدد من هذه الدراسات

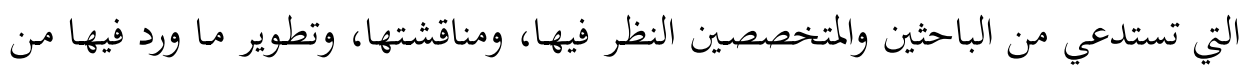

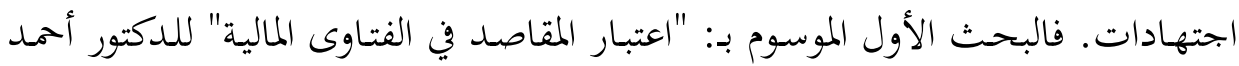

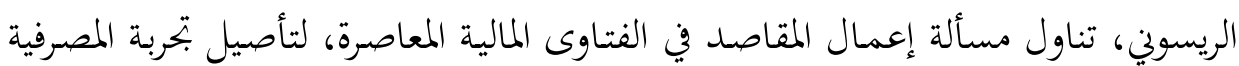
الإسلامية، وتمكينها من الخروج عن الرؤية الرأسمالية الغربية، التي نشأت تلك التجربة في

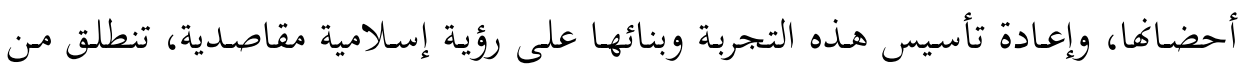

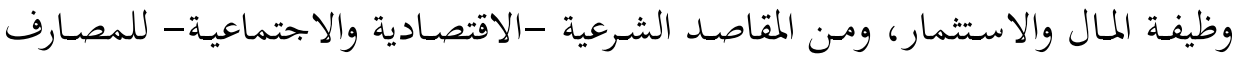
الإسـلامية. ضـارباً الأمثلـة على مكانـة المقاصــ في فتـاوى الميئـات الماليـة الإسـلامية في

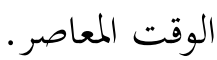

وحاول الدكتور جاسر عودة في بحثه المعنون بـ: "توظيف مقاصد الشريعة في ترشيد

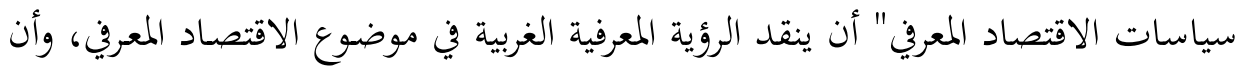

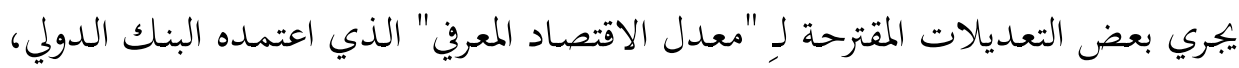
بــا يتوافـق مــع مقاصــ الشـريعة الإسـلامية، الـتي تـوازن بــن الضــروريات والحاجيـات والتحسينيات، وصولاً إلى تحقيق التنمية الإسلامية المتوازنة المنشودة.

وكشف الدكتور عبد الرزاق بلعباس في بحثه الذي جاء بعنوان: "الاقتصاد الإسلامي

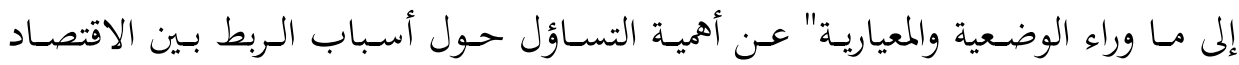

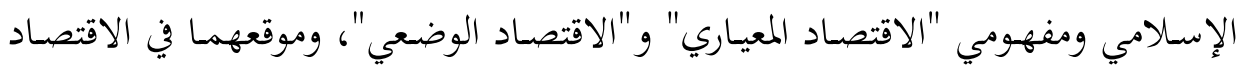




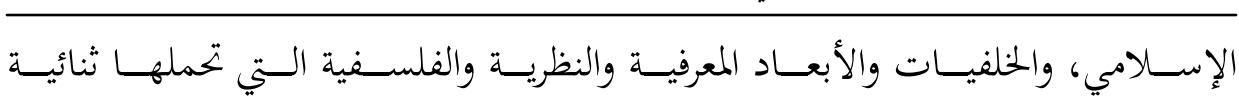

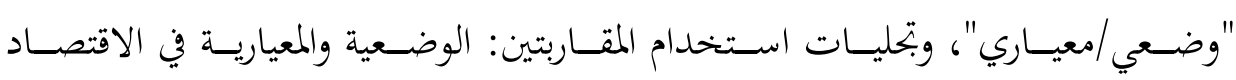

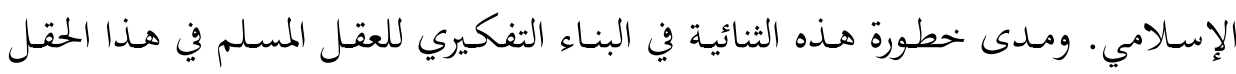
المعرئ.

أمـا البحـث الرابع فكان بعنوان: "إثـكالية المصـارف الإسـلامية مـا بـين الـمُسنعِف

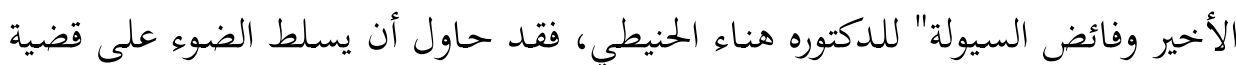

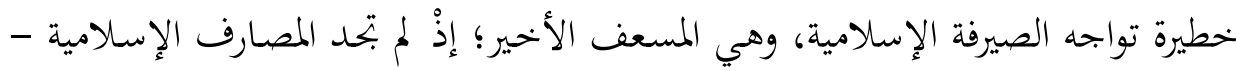

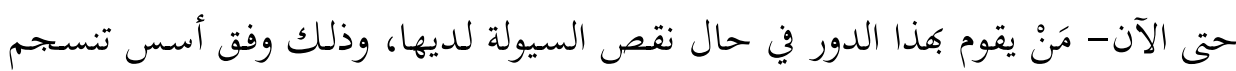

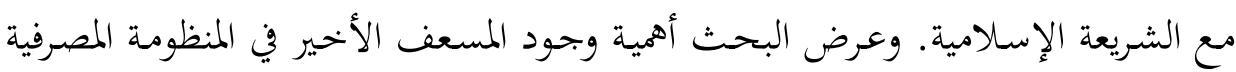

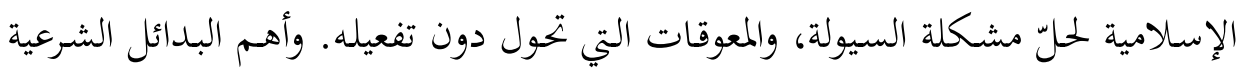
القابلة للتطبيق، التي تتيح للمصرف المركزي الاضطلاع بوظيفة المُسْعِف الأخير. واستكمالاً لغرض هذا العدد جاء باب قراءات ومراجعات متضمناً مراجعة لكتابين

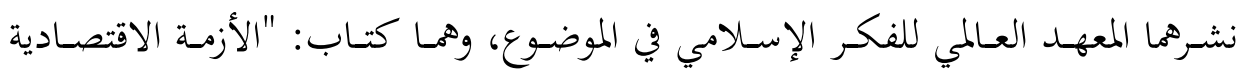

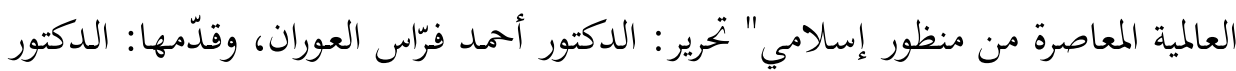
غسان الطالب. وكتاب: "السياسة النقدية بين الفقه الإسلامي والاقتصاد الوضعي" لمؤلفه منه الدكتور وليد شاويش، وقدّمتها الدكتوره هناء الحنيطي. وفي العدد حلقة جديدة مـن عروض مختصرة لعدد من الكتب التي صدرت حديثاً، ذات صلة بالاقتصاد الإسلامي. نسأل الله أن ينفع بهذا بمادة هذا العدد ويجزي كل من أسهم فيه بعمل، والحمد لله رب العالمين. 